\title{
Sex differences in performance and associated cardiac activity during a reaction time task
}

\author{
MICHAEL G. H. COLES, STEPHEN W. PORGES, and CONNIE C. DUNCAN-JOHNSON \\ University of Illinois, Champaign, Illinois 61820
}

\begin{abstract}
Measures of reaction time and cardiac activity were recorded from 10 males and 10 female subjects during a variable foreperiod reaction time task. Males showed faster reaction times, greater cardiac decelerations, and higher levels of heart-rate variability during the foreperiod. Trend analyses revealed sex differences in the heart-rate response to the onset of the warning signal, but not in the response to the imperative signal. These results indicate that those measures of cardiac activity which have been shown previously to predict performance tend to differentiate between the sexes when there are sex differences in performance.
\end{abstract}

One of the most commonly used paradigms in the study of the relationship between psychological functions and physiological responses has been the simple reaction time (RT) task. Several investigators (e.g., Lacey \& Lacey, 1970; Obrist, Webb, \& Sutterer, 1969) have reported that performance in fixed foreperiod RT tasks is correlated with foreperiod physiological activity. In particular, subjects with fast RTs have larger foreperiod cardiac decelerations than slow subjects. In a variable foreperiod task, Porges (1972) found a relationship between aspects of heart-rate variability and performance. Subjects with high pretrial levels of heart-rate variability and those who showed large reductions in variability during the foreperiod reacted faster than their counterparts.

Since females have been shown to have slower RTs than males (Seashore \& Seashore, 1941; Bellis, 1933), it might be expected that the two sexes will also show differences in those parameters of physiological activity which have been found to predict performance. The aim of the present study is to examine this possibility. Specifically, it is predicted that in a task where females show slower reaction times than males, measures of cardiac deceleration and heart-rate variability will differentiate between the sexes.

\section{METHOD}

\section{Subjects}

Ten male and ten female undergraduate students (ages 18-21 years) enrolled in the introductory psychology course at the University of Illinois at Urbana-Champaign serv? as subjects. All subjects participated in the experiment to fulfill a course requirement, and although they were free to refuse to participate, none did so.

This research was partially supported by Grants MH 23183-01 from NIMH and NE-6-00-3-0013 from NIE. The authors would like to acknowledge the assistance of Michael $N$. Cheung in the analysis of the data.

Address requests for reprints to Michael G. H. Coles, Department of Psychology, University of Illinois, Champaign, Illinois 61820 .

\section{Apparatus and Procedure}

Each subject reported individually for the experimental session and was seated in a high-backed easy chair in a partially sound-proofed, air-conditioned room. A Beckman R-411 Dynagraph and Beckman electrodes were used to provide a continuous recording of the subjects' heart beats on chart paper and on a Hewlett-Packard 3960 FM tape recorder.

The subjects were required to perform a series of $36 \mathrm{RT}$ trials. Each trial began with the illumination of a red light, placed $3 \mathrm{ft}$ in front of the subject and terminated with light offset. The subject was instructed to close a microswitch with his dominant hand as soon as possible after light offset. The foreperiod was randomly varied among 12,18 , and $24 \mathrm{sec}$, and intertrial interval varied between 15 and $25 \mathrm{sec}$. The subject's RT was recorded on a Hunter Klockounter which measured the latency between light offset and the subject's response. Five practice trials and a 3-min rest period were given before the trial series began.

\section{Scoring}

Twenty-four second-by-second heart-rate values on each trial were obtained by using an IBM 1800 computer and procedures described by Coles (1972). These values represented heart rate for the $6 \mathrm{sec}$ before and after warning-signal onset and for the $6 \mathrm{sec}$ before and after warning-signal offset. In addition, the mean and standard deviation of a 20 -sec heart-rate sample was obtained for the last $20 \mathrm{sec}$ of the rest period.

\section{RESULTS}

Males showed significantly faster average RTs than females over the 36 trials $(290 \mathrm{msec}$ vs. $350 \mathrm{msec})$, $\mathrm{F}(1,18)=11.56, \mathrm{p}<.01$.

For each subject, averaged second-by-second heart-rate values were derived across the 36 trials. These data, for males and females separately, are shown in Figure 1. For the purpose of analysis, second-by-second heart-rate values, means, and standard deviations were obtained for each of the four within-trial 6-sec periods labeled A, B, C, and D in Figure 1.

The heart-rate response to the onset and offset of the warning signal was evaluated by a second-by-second analysis. For each subject, heart rate during each second in Period B and Period D was calculated as the magnitude of change in beats per minute from the mean of Period A. The data for these second-by-second 


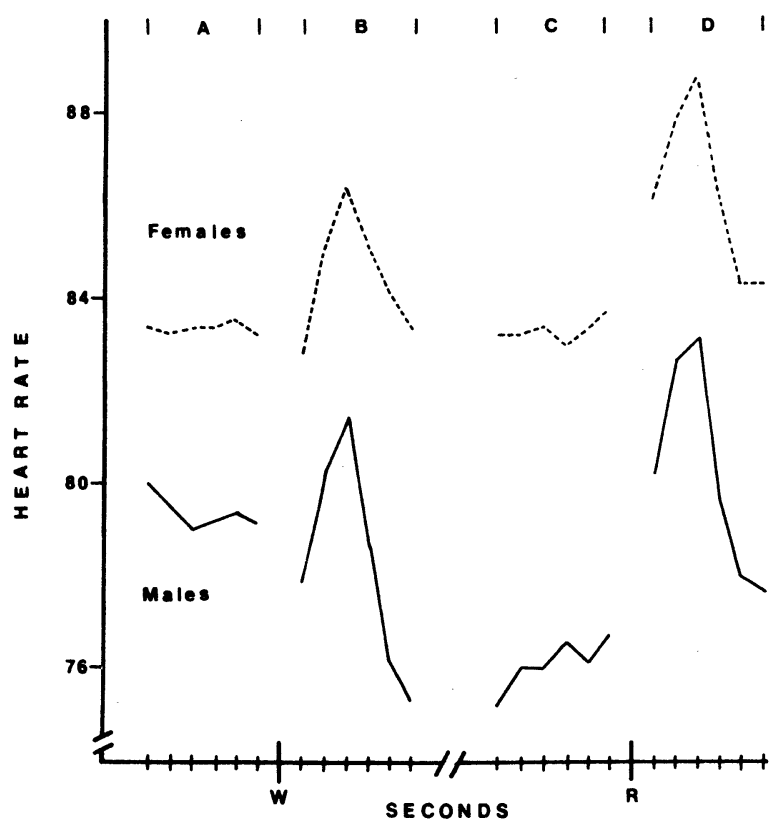

Figure 1. Averaged second-by-second heart-rate values for males and females. " $W$ " and " $R$ " indicate points of onset and offset of the warning signal.

responses were blocked into six trial blocks for analysis. The response to the onset of the warning signal was characterized by a significant seconds effect, $F(5,90)=16.5, p<.01$. This pattern was reflected in significant quadratic, $F(1,18)=12.8$, and quartic, $\mathrm{F}(1,18)=16.7$ components of a trend analysis. The second-by-second response pattern which is illustrated in Figure 1 differed significantly between the two sexes, $F(5,90)=3.8, p<.01$. The trend analysis indicated a significant Sex by Pattern interaction on the cubic component, $\mathrm{F}(1,18)=5.3, \mathrm{p}<.05$. A test for simple effects on this interaction indicated significant cubic components only for the females. The heart-rate response pattern to the warning-signal onset changed as a function of trial blocks, $F(25,450)=2.2, p<.01$. This changing pattern was reflected in the changing significant trend components across trial blocks, al though all trial blocks reflected a significant quartic trend.

The response to the offset of the warning signal was characterized by a significant seconds effect, $F(5,90)=20.2, p<.01$. There were no sex differences in this response pattern, which is also illustrated in Figure 1 . The trend analysis indicated significant linear, $F(1,18)=4.96$, quadratic, $F(1,18)=26.7$, and cubic, $\mathrm{F}(1,18)=26.6$ components. The response pattern changed over trial blocks, $\mathrm{F}(25,450)=2.3, \mathrm{p}<.01$, although all trial blocks reflected a significant quadratic trend. Besides this pattern change over trial blocks, there was a significant main effect of trial block, $F(5,90)=95.9, p<.01$. This effect may be described by a reduction of the mean acceleration as a function of time.

Analyses of variance were performed to test for sex differences in mean heart rate and mean-heart-rate variability during the four periods collapsed over the 36 trials. Heart-rate variability was defined as the standard deviation of the 6-sec heart-rate sample of each period. Males and females showed a differential change in mean heart rate from Period A to Period $B, F(1,18)=10.59$, $\mathrm{p}<.01$. The males exhibited a decrease in heart rate and the females an increase. The sexes also differed in their response from Period A to Period $\mathrm{C}$; males exhibited a greater decelerative response, $\mathrm{F}(1,18)=15.1, \mathrm{p}<.01$. For all periods, males showed higher levels of heart-rate variability than females with significant differences between the sexes on Periods B, C, and D. Although the reduction in heart-rate variability from Period $\mathrm{A}$ to $\mathrm{C}$ approached significance, $F(1,18)=4.35, p=.06$, the sexes did not differ. Eighty percent of the females and $90 \%$ of the males exhibited lower heart-rate variability during Period $\mathrm{C}$ than during Period A.

Although males showed higher levels of heart-rate variability and lower levels of heart rate during the rest period, this difference was not significant, nor was the sex difference in overall heart rate during the task (see Figure 1). However, for females, heart rate decreased from the rest-period level to the level during task, while there was no change for the males. This sex difference was significant, $F(1,18)=10.14, p<.01$.

\section{DISCUSSION}

Consistent with previous research, males had significantly faster RTs than females. The physiological data suggest that the heart-rate responses of the males and females parallel the performance difference. This was reflected in the higher heart-rate variability and larger heart-rate reductions during the task for the males. These responses are consistent with the various theoretical positions (Lacey, 1967; Porges, 1972, 1973) regarding the relationship between heart-rate responses and reaction time.

There were also sex differences in the heart-rate response pattern to the warning-signal onset. The males showed a larger decelerative component. This finding was statistically supported by sex differences in the trend analysis. However, in response to the warning-signal offset, the sexes did not differ. It is possible that the heart-rate response pattern to onset reflects a sex difference in preparation to respond while the response to offset reflects the coupling of the cardiac system with the somatic responses associated with the button press. Supporting the differential significance of the two responses is the evidence that their shapes are primarily characterized by different orthogonal components, the onset response by a quartic trend and 
the of fset response by a quadratic trend.

The physiological data suggest that the cardiac activity of males may exhibit more plasticity in terms of responsiveness and spontaneous activity, but that this sex difference is confined to showing appropriate responses to task demands. This is consistent with the sex differences reported by Young and Blanchard (1972) in their study of instrumental heart-rate conditioning. It is impossible to determine within the context of the present study whether the reported sex differences reflect a fundamental difference in the ability to generate appropriate physiological and behavioral responses in task situations or are a function of cultural and motivational factors. Motivational factors can affect both heart-rate changes and reaction time (Lacey \& Lacey, 1970).

Between-subject correlations for RT and different aspects of physiological activity were computed separately for each sex. These included mean heart rate and heart-rate variability for Period $A$, decrease in heart-rate variability and heart rate from Periods $\mathrm{A}$ to $\mathrm{C}$, and resting-level heart rate and heart-rate variability. These correlations were uniformly nonsignificant, although for the most part they were in the direction predicted from Porges (1972) and Lacey and Lacey (1970). It is paradoxical that the correlational data indicated that physiological variables which discriminated between the groups did not predict within-sex differences in RT. This, however, may be attributable to the relatively homogeneous composition of the subjects within each sex which led to a restricted range of RTs.

\section{REFERENCES}

Bellis, C. J. Reaction times and chronological age. Proceedings of the Society of Experimental Biology and Medicine, 1933, 30, 801-803.

Coles, M. G. H. Cardiac and respiratory activity during visual search. Journal of Experimental Psychology, 1972, 96, 371-379.

Lacey, J. I. Somatic response patterning and stress: Some revisions of activation theory. In $M$. $H$. Appley and $R$. Trumbell (Eds.), Psychological stress: Issues in research. New York: Appleton-Century-Crofts, 1967.

Lacey, J. I., \& Lacey, B. C. Some autonomic-central nervous sytem interrelationships. In P. Black (Ed.)Physiological correlates of emotion. New York: Academic Press, 1970.

Obrist, P. A., Webb, R. A., \& Sutterer, J. R. Heart rate and somatic changes during aversive conditioning and a simple reaction time task. Psychophysiology, 1969, 5, 696-723.

Porges, S. W. Heart rate variability and deceleration as indexes of reaction time. Journal of Experimental Psychology, 1972, 92. 103-110.

Porges, S. W. Heart rate variability: An autonomic correlate of reaction time performance. Bulletin of the Psychonomic Society, 1973, 1, 270-272.

Seashore, S. H., \& Seashore, R. H. Individual differences in simple auditory reaction times of hands, feet and jaws. Journal of Experimental Psychology, 1941, 29, 342-345.

Young, L. D., \& Blanchard, E. B. Sex differences in the ability to control heart rate. Psychophysiology, 1972, 9, 667-668.

(Received for publication May 14, 1974; revision received November 4,1974 .) 